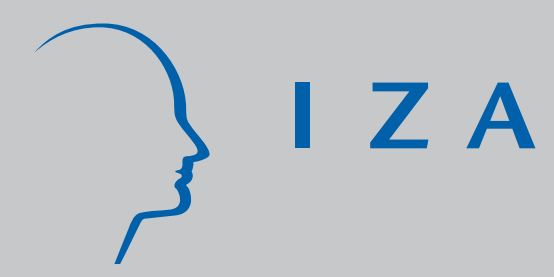

IZA DP No. 1019

Public Infrastructure as a Determinant

of Intertemporal and Interregional

Productive Performance in China

Feng-Cheng Fu

Chu-Ping C. Vij verberg

Wim P. M. Vijverberg

February 2004 


\title{
Public Infrastructure as a Determinant of Intertemporal and Interregional Productive Performance in China
}

\author{
Feng-Cheng Fu \\ Chung-Hua Institute for Economic Research \\ Chu-Ping C. Vijverberg \\ University of Texas at Dallas \\ Wim P. M. Vijverberg \\ University of Texas at Dallas \\ and IZA Bonn \\ Discussion Paper No. 1019 \\ February 2004 \\ IZA \\ P.O. Box 7240 \\ 53072 Bonn \\ Germany \\ Phone: +49-228-3894-0 \\ Fax: +49-228-3894-180 \\ Email: iza@iza.org
}

\begin{abstract}
Any opinions expressed here are those of the author(s) and not those of the institute. Research disseminated by IZA may include views on policy, but the institute itself takes no institutional policy positions.

The Institute for the Study of Labor (IZA) in Bonn is a local and virtual international research center and a place of communication between science, politics and business. IZA is an independent nonprofit company supported by Deutsche Post World Net. The center is associated with the University of Bonn and offers a stimulating research environment through its research networks, research support, and visitors and doctoral programs. IZA engages in (i) original and internationally competitive research in all fields of labor economics, (ii) development of policy concepts, and (iii) dissemination of research results and concepts to the interested public.
\end{abstract}

IZA Discussion Papers often represent preliminary work and are circulated to encourage discussion. Citation of such a paper should account for its provisional character. A revised version may be available on the IZA website (www.iza.org) or directly from the author. 
IZA Discussion Paper No. 1019

February 2004

\section{ABSTRACT \\ Public Infrastructure as a Determinant of Intertemporal and Interregional Productive Performance in China}

This paper focuses on the question whether public infrastructure capital matters for labor productivity in China, both over time and across regions. It finds that public infrastructure is a significant determinant of variations in labor productivity across provinces, but the contribution of public capital to labor productivity growth over time is likely non-existing or even negative. These seemingly contradictory results are reconciled once we view the measured intertemporal effect as a short-run impact and the interregional effect as a longterm consequence of public infrastructure investment.

JEL Classification: H54, O47, R11

Keywords: public infrastructure, labor productivity, China

Corresponding author:

Wim P. M. Vijverberg

School of Social Sciences

University of Texas at Dallas

P.O. Box 75083-0688

Richardson, TX 75083-0688

USA

Email: vijver@utdallas.edu 


\section{Public Infrastructure as a Determinant of Intertemporal and Interregional Productive Performance in China}

\section{Introduction}

Does public infrastructure capital have a significant impact on productivity in the industrial sector? This issue has been debated for more than a decade with data from various Western countries (Gramlich, 1994). If the productivity of an enterprise (either privately or publicly owned) is indeed significantly affected by the provision of infrastructure in the region, investment in infrastructure is one avenue by which a society can increase its productivity. Otherwise, productivity growth must come from other kinds of improvements.

In China, most enterprises are government-owned and thus most capital is considered as public capital, but the issue of the impact of public infrastructure on productivity remains valid. Moreover, as is well-known, income or productivity differentials in different regions of China are strongly affected by geography and national resource endowments (e.g., Demurger, 2001; Wei and Wu, 2001; Wei, 2002). Thus, if public infrastructure proves to be a significant contributor to productivity growth, investment in public infrastructure in specific regions can be a useful policy tool to reduce income gaps in various regions of China. Indeed, the purpose of this paper is to determine the size of the impact of public infrastructure on productivity growth. While the focus of this paper is not to explain the original income discrepancy or productivity growth disparity in various regions, we employ analytical tools that are evaluated by their ability to predict productivity growth over time and across provinces. We use pooled time-series/cross-sectional data (1994-2000) to maximize information from the available data and to minimize the impact of measurement error. 
The paper proceeds as follows. After a brief literature survey and an overview of economic conditions in China (Section II), we take a first look at the level and growth rate of labor productivity (output per worker) in Section III. There is little evidence of convergence in the level of labor productivity: regions with low levels of productivity typically do not have the fastest growth rates. We present preliminary evidence about the causes of variation in labor productivity across provinces over time. Section IV examines the sources of labor productivity growth through the cost function and profit function approach. Growth in the productivity of labor may be generated by changes in the capital-labor ratio, by labor force growth, by investments in public infrastructure, and by improvements in "technology" (interpreted broadly). In Section V, we estimate the cost and profit function models, and we measure the impact of public infrastructure on labor productivity both over time and across regions. As argued in Sections V and VI, the evidence suggests that the cost function model yields more plausible results; the profit function model depends heavily on output data that, in China, may be subject to too many extraneous shocks to be useful in this econometric model. According to the cost function model, public capital is a significant determinant of variations in labor productivity across provinces, but the contribution of public capital to labor productivity growth over time is likely non-existing or even negative. These seemingly contradictory results are reconciled once we view the measured intertemporal effect as a short-run impact and the interregional effect as a long-term consequence of public infrastructure investment.

\section{Background}

\section{II.1 Related Literature}

The notion that the provision of public infrastructure capital contributes to the private sector's 
economic activity is not new, going back to, e.g., Mead (1952). In the U.S., the declining provision of public capital in the 1970s and the concurrent decline in the growth of private sector's productivity revived the research in this area. Economists questioned whether the decline in private sector productivity growth derives from the declining rate of public capital investment. Studies in the U.S. yielded mixed results. On the basis of time series data, some (e.g., Aschauer 1989, 1990; Munnell 1990ab, 1992; Lynde and Richmond 1993; Morrison and Schwartz, 1996) found that public capital did contribute to the private sector's productivity. These studies are characterized by different econometric approaches and different data sets without overlap to enable comparison of the estimates between studies. Vijverberg, Vijverberg and Gamble (1997) applied three different approaches to one data set and concluded that a firm conclusion could not be achieved because of the problem of multicollinearity in the time series data; see also Moreno, Lopez-Bazo, and Artis (2002), and Vijverberg and Vijverberg (2003). In addition, the production function approach was most unreliable while cost and profit function models gave more consistent results.

The generally disappointing experience with time series data led to a consensus that there is more hope in cross-sectional or pooled cross-section time-series samples, where the variation among states or provinces could be explored. However, the results again are mixed. Some (Hulten and Peterson, 1984; Costa, Ellson, and Martin, 1987; Holtz-Eakin, 1994; Garcia-Mila, McGuire, and Porter, 1996) asserted that the relevance of public infrastructure for private productivity is debatable while others found that public infrastructure has a positive impact on private productivity (Deno 1988; Munnell 1990b; Garcia-Mila and McGuire, 1992; Boisso, Grosskopf, and Hayes, 2000). A disadvantage of pursuing this avenue is that there exist acute public capital endogeneity issues (wealthy states can spend more on public capital 
investments) and out-of-state public capital spillover effects (Gramlich 1994:1189; Moreno et al. 1998). ${ }^{1}$

At the international level, most but not all studies use pooled cross-sectional time series data. The methods vary from Vector Auto-Regression (VAR) and Data Envelopment Analysis (DEA) to the production function approach and the cost function method. Most results showed that public infrastructure has a positive impact on productivity. ${ }^{2}$

As for China, Demurger (2001) estimated a Barro-type (1990) regression equation that is best interpreted in the context of the production function approach. With data on 24 provinces and autonomous regions over the period 1985-1998, she found that transport infrastructure and telecommunication facilities impact the growth of productivity. Her finding is of special interest, because our study uses data from China as well. As mentioned earlier, the production function approach appears to be less reliable than the cost and profit function models (Vijverberg, Vijverberg and Gamble, 1997). To ensure that public infrastructure indeed has a positive impact on productivity, we need to use cost and profit function methods for confirmation. We employ data of 30 provinces and autonomous regions over the period from 1994 to 2000. As we shall see, there is a large amount of interprovincial variation in the data, which should help in identifying the possible effect of public capital on industrial productivity. We do not attempt to deal with endogeneity issues and spillover effects, since adequate data are simply out of reach, but in our analysis of

\footnotetext{
1 Demetriades and Mamuneas (2000) use a panel of 12 OECD countries over the period 1972-1991 and found that public infrastructure capital has a positive impact on output. This research strategy exploits the between-country variation in the determinants in the same way that a panel of state data would and at the same time avoids the cross-state interdependencies. However, it also assumes that production technology is identical across countries, which is a stronger statement than the assumption that technology is the same across provinces or states within a nation.

2 See, for example, Canada (Wylie, 1996), East Asia (Wang, 2002), Greece (Rovolis and Spence, 2002), India (Mitra, Varoudakis and Veganzones-Varoudakis, 2002), Korea (Kim, Koo and Lee,1999), Mexico (Shah, 1992), the Netherlands (Strum, Jacobs and Groote, 1999), OECD countries (Demetriades and Mamuneas, 2000), Spain (Mas et al., 1996; Moreno, Lopez-Bazo, and Artis, 2002), Sweden (Berndt and Hansson, 1992), and West Germany (Conrad and Seitz, 1994; Kemmerling and Stephan, 2002).
} 
cost and profit function models we do allow for cross-province spatial correlations in the disturbances.

\section{II.2 Context ${ }^{3}$}

The economy of China underwent a thorough transformation over the past two decades, and it is useful to highlight some features and events that may impact the results of the analysis before we take a look at the data that cover the period 1994-2000. Reforms that started in the late 1970s set in motion a process of rapid economic growth, but the growth path was not entirely smooth. In the beginning, China initiated a reform of the micro-management institution, allowing enterprises and farmers a great degree of autonomy. This inevitably demanded corresponding changes in the resource allocation mechanism and the macropolicy environment. Due to the soft-budget constraint in state-owned enterprises (SOEs), the reforms in the macro-policy environment led to overheating of the economy. For example, after decades of low inflation, prices rose by 18 percent annually in 1988 and 1989, a period that was then followed by diminished growth in 1990 and 1991. The experience in 1980s convinced China's authorities that its economic reforms needed to resolve the conflicts between macro-policy environment and micro-management system.

The turbulence of this period generated uncertainty about the durability of the reform efforts, but after assurances in 1992 from Deng Xiaoping and the Party Congress that China sought to become a socialist market economy, economic activity revived with dramatic increases in both domestic and foreign investment. This heated up the economy once again, led to another period of high inflation in 1993-1995, and consequently prompted efforts to slow down the economy to a "soft landing" by means of credit tightening. The non-state productive sector (including, e.g., township-village enterprises) was affected the 
most; SOEs were still able to borrow, in a forced manner because the state banks covered SOE losses in this way. The East Asian financial crisis hit in late 1997, domestic consumption fell, and exports declined. Inflation turned to deflation by 1998, and China started pursuing an expansionary fiscal policy, especially through large-scale investments in public infrastructure.

In 1997, 70 to 80 percent of bank loans were given to SOEs, and the proportion of bad loans was 40 percent or more. This heavy drain on financial resources prompted a directive in 1998 by Premier Zhu Rongji to accelerate the reform of SOEs, ${ }^{4}$ making efficient enterprises more profitable, merging some where appropriate, and closing those that generate persistent losses. SOEs are in a difficult position, as they also provide education and health care to workers and their households. Thus, they pay for a substantial number of support personnel that a typical private sector enterprise is not burdened with. The SOE directive led to substantial numbers of layoffs, but as SOEs were still responsible for the retraining of the workers they laid off, their operating costs did not really decline much in the short run. There also was a stronger incentive to inflate reported revenues in order to avoid being liquidated. Over the years, about one-third of the SOEs showed a net loss in their account, another one-third showed a net profit on their books but are actually losing money in real terms, and the remainder generated real profits.

Our data cover all of China's 30 provinces, autonomous regions, and municipalities. As is well known, the disparity between the eastern and western provinces and between rural and urban areas is great. For example, in 1998, per capita living expenditures varied from 710 yuan in Tibet to 2891 yuan in Zhejiang (and even up to 4207 yuan in Shanghai). The disparity grew over time, even during the 1990s

3 This section draws on Chow (2003), Dickinson (2003), Hughes (2002), Lin, Cai and Li (1996), and Preston and Xing (2003).

4 At the same time, micro-management reforms were included on the agenda as well. 
when China's central government paid a lot of attention to regional economic development. In fact, it used economic performance as one of the criteria in the evaluation and promotion of local government officials, who in turn would sometimes exaggerate local output data. Usually, after reevaluation by the Central Bureau of Labor Statistics, the output numbers are smaller that those in the original reports.

The next section describes our data in detail and provides preliminary evidence on the research question.

\section{Data and Preliminary Regression Results}

\section{III.1 Description of the Data}

The data represent the 22 provinces of China as well as 5 autonomous regions and 3 municipalities directly under the control of the central authorities. (For ease of discussion, we shall refer to these 30 geographical units as provinces.) The sample period ranges from 1994 to 2000 — or from 1993 to 2000 whenever information on physical capital is not needed. This study focuses on productive activity in industrial firms with independent accounting systems, as reported in the various issues of China Statistical Yearbook. Variables include value added, the number of workers, the wage bill, the net value of fixed assets, investment in fixed assets of transportation, storage, posts, and telecommunications, and various price indices. The information on investment in fixed assets of transportation, storage, posts, and telecommunications is converted by means of the perpetual inventory method into a stock of fixed assets, which represents our measure of public capital $G$. For further information, see the Appendix.

\section{III.2 Labor Productivity in China}


Let us now examine variations in labor productivity in the industrial sector in China. To be precise, what is called the industrial sector covers productive organizations with independent accounting systems. Table 1 presents trends in labor productivity and a few of its determinants. Labor productivity was stagnant up to 1995, rose sharply during 1996 and 1997, took a leap in 1998 (corresponding with the layoffs that happened in 1998), was steady in 1999, and leaped again in 2000. By comparison, the growth in the capital labor ratio was steady and rapid. Similarly, the stock of public infrastructure capital grew by roughly 20 percent per year, more slowly early in the 1993-2000 period and faster later on. ${ }^{5}$ The labor force of this sector remained roughly constant until 1998 when a sharp drop of about 25 percent $(490,000$ workers in an average province) occurred. Subsequently there was a further reduction in 1999 and 2000 by about 100,000 workers per province each year.

Since it is too difficult to illustrate labor productivity growth in each province, we divide the 30 provinces into three groups of 10 provinces each according to the value of their labor productivity, averaged between 1993 and 1994 to reduce the impact of measurement error. Of the twelve provinces on the east coast of China, eight belong to the highest group. The central and western provinces are equally scattered among the middle and lowest groups. Figure 1 shows the evolution of labor productivity in each group. For each group, three lines are drawn, representing from top to bottom the $80^{\text {th }}, 50^{\text {th }}$, and $20^{\text {th }}$ percentile of the value of labor productivity among the ten group members in a given year. Thus, labor productivity in each group was stagnant until 1995 (and in fact declining for the middle group) and rose afterwards. Most of the top group stayed ahead of the rest of the country: only the fastest growers in the middle group caught up with the slowest members of the highest group. However, the fastest growers in the lowest group

\footnotetext{
${ }^{5}$ Demurger (2001) has a rich discussion of the recent history of infrastructure provision in China.
} 
exceeded the median of the middle group for most of the 1994-2000 period, and the slowest growers of the middle group managed to do no better than the median of the lowest group. In other words, the differentiation between the middle and lowest groups that was made on the basis of the 1993/94 productivity level faded somewhat.

Altogether, there are sharp differences in the growth in labor productivity, both over time and among provinces, and, over this period at least, there is little evidence of convergence in the level of labor productivity. This makes it all the more interesting to examine the determinants of labor productivity. For a first attempt at this examination, we turn to Table 2, presenting the estimates of a random effects model that explains variation in industrial labor productivity on the basis of the variables listed in equation (2) below. Thus, the level of labor productivity is strongly influenced by (i) the capital labor ratio, (ii) the stock of public infrastructure capital, (iii) a varying time trend, and (iv) persistent variations across provinces. The time trend is not linear: given the other factors, labor productivity was highest in 1994 and dipped sharply in 1999, which corresponds with the macroeconomic cycle outlined in Section II.2 above. The persistent variation among provinces was of course already evident in Figure 1 but is indicated here by the large magnitude of the variance of the random effect relative to the variance of the disturbance. Somewhat surprisingly, contrary to the suggestion of the trends in the descriptive statistics in Table 1, the size of the labor force does not matter.

Finally, the Hausman test fails to reject the random effects specification in favor of the fixed effect specification. $^{6}$ This is notable since, as suggestive as this regression model is, it assumes that capital and

6 Demurger tested a random effects specification of her model and rejected it in favor of a fixed effects model. The two models differ substantially, though. Her model is estimated on data from a smaller province set from 1985 to 1998 , has a different set of explanatory variables, and contains a random effect for time as well as for provinces. Regarding the latter, 
labor are exogenous determinants of output and labor productivity, contrary to standard microeconomic models of firm behavior. Indeed, one can hardly assume that capital and labor allocations are independent of production outcomes, even in China with its centralized system of command - and it should be noted that market forces are becoming more important especially during this period. In the regression model, endogeneity would be expected to express itself in a correlation of the random effects with the explanatory variables and thus cause bias, but this is not evident here. Even so, without a separate analysis of the labor productivity trends with the standard cost and profit function approaches that have been used elsewhere in the literature as discussed in Section II, the evidence in Table 2 remains not fully convincing. Thus, in the next sections of the paper, we will analyze these data also with the cost and profit models.

\section{Cost and Profit Function Models}

The impact of infrastructure capital on private productivity is examined with two different models, namely, the cost function model and the profit function model. Both of these models are based on the same production relationship:

$$
Y=F(L, K, G, t)
$$

where $Y$ is regional output or total output, produced with inputs $L$ (labor), $K$ (capital), and $G$ (public infrastructure capital). The variable $t$ represents the level of technology. Let $p_{I}$ be the price of $I$ for $I=Y, L, K$; and define real prices $r_{I}=p_{I} / p_{Q}$ for $I=L, K$.

To compute the change in labor productivity, differentiate (1) totally as follows:

our model contains a fixed effect for time; thus we fail to reject the notion of provincial random effects. 


$$
\frac{d(Y / L)}{Y / L}=\frac{F_{K} K}{Y}\left(\frac{d K}{K}-\frac{d L}{L}\right)+\left(\frac{F_{L} L}{Y}+\frac{F_{K} K}{Y}-1\right) \frac{d L}{L}+\frac{F_{G} G}{Y} \frac{d G}{G}+\frac{F_{t}}{Y} d t
$$

or in short:

$$
\frac{d(Y / L)}{Y / L}=\Delta_{K / L}+\Delta_{L}+\Delta_{G}+\Delta_{t}
$$

Frequently, the last two terms are combined to measure the change in multifactor productivity: $\Delta_{M F P}=\Delta_{G}+\Delta_{t}$. Thus, the change in labor productivity is decomposed in three terms: the effects of changes in the capital labor ratio, the size of the labor force, and the multifactor productivity growth $\left(\Delta_{M F P}\right)$, which itself contains the effect of the volume of public capital and technological change. The labor force effect disappears if $F$ is linear homogeneous in $L$ and $K$.

\section{III.1 The Cost Function Model}

Define cost as $C=p_{L} L+p_{K} K$. With competitive input markets and cost-minimizing behavior, $\mathrm{C}$ can be expressed as:

$$
C=C\left(p_{L}, p_{K}, Y, G, t\right)
$$

with $\partial C / \partial p_{I}=I$, for $I=L, K$. Define the cost share of input $I$ as $\sigma_{I}=p_{I} I / C$. Then, $\sigma_{L}+\sigma_{K}=1$.

On the basis of cost-minimizing behavior, the cost shares can also be expressed as $\sigma_{I}=\partial \ln C / \partial \ln p_{I}$. Furthermore, in competitive output markets, $\partial C / \partial Y$ equals $p_{Y}$, which implies that the "output share" $\sigma_{Y}=p_{Y} Y / C$ equals $\partial \ln C / \partial \ln Y$

Given competitive output markets and cost-minimization assumptions, it is trivial to show that $\partial C / \partial G=-p_{Y} F_{G}$, and $\partial C / \partial t=-p_{Y} F_{t}$, and, of course, $p_{Y} F_{I}=p_{I}$ for $I=L, K$. Together with the definitions of $\sigma_{G}=\partial \ln C / \partial \ln G$ and $\sigma_{t}=\partial \ln C / \partial \ln t$, equation (2) becomes: 


$$
\frac{d(Y / L)}{Y / L}=\frac{\sigma_{K}}{\sigma_{Y}}\left(\frac{d K}{K}-\frac{d L}{L}\right)+\frac{1-\sigma_{Y}}{\sigma_{Y}} \frac{d L}{L}-\frac{\sigma_{G}}{\sigma_{Y}} \frac{d G}{G}-\frac{\sigma_{t}}{\sigma_{Y}} d t
$$

For estimation, we specify a translog cost equation (however, without $[\ln G]^{2}$ and $t[\ln G]$ in order to avoid overspecification) and derive the labor share, and output share equations from it. Thus:

$$
\ln C=\alpha_{0}+\alpha^{\prime} x+0.5 x^{\prime} B x
$$

where $x^{\prime}=\left(\ln w, \ln p_{K}, \ln Y, \ln G, t\right), \alpha^{\prime}=\left(\alpha_{L},-\alpha_{L}, \alpha_{Y}, \alpha_{G} \alpha_{t}\right)$, and

$$
\mathrm{B}=\left(\begin{array}{ccccc}
\beta_{L L} & -\beta_{L L} & \beta_{L Y} & \beta_{L G} & \beta_{L t} \\
-\beta_{L L} & \beta_{L L} & -\beta_{L Y} & -\beta_{L G} & -\beta_{L t} \\
\beta_{L Y} & -\beta_{L Y} & \beta_{Y Y} & \beta_{Y G} & \beta_{Y t} \\
\beta_{L G} & -\beta_{L G} & \beta_{Y G} & 0 & 0 \\
\beta_{L t} & -\beta_{L t} & \beta_{Y t} & 0 & \beta_{t t}
\end{array}\right)
$$

The share equations are then specified using parameters from $\alpha$ and $\mathrm{B}$ above:

$$
\begin{aligned}
& \sigma_{L}=\alpha_{L}+B_{L} x \\
& \sigma_{Y}=\alpha_{Y}+B_{Y} x
\end{aligned}
$$

where $\mathrm{B}_{L}$ and $\mathrm{B}_{Y \text {. }}$ are the first and third rows of matrix $\mathrm{B}$.

To the three equations of the model (6), (7), and (8), we add disturbance terms. In section IV.3, we discuss distributional assumptions. The three equations are then estimated jointly, imposing the implied cross-equation parameter restrictions.

\section{IV.2 The Profit Function Model}

Profit is defined as (Deno 1988; Lynde and Richmond 1993): $\Pi=p_{Y} Y-p_{L} L-p_{K} K$. In competitive input and output markets and profit-maximizing behavior, ? can also be expressed as:

$$
\Pi=\Pi\left(p_{Y}, p_{L}, p_{K}, G, t\right)
$$


from which we have $\partial \Pi / \partial p_{Y}=Y$, and $\partial \Pi / \partial p_{I}=-I$ for $I=L, K$. Moreover, $\partial \Pi / \partial G=p_{Y} F_{G}$, and $\partial \Pi / \partial t=p_{Y} F_{t}$. Let us then define "profit ratios" as $s_{I} \equiv p_{I} I / \Pi$ for $I=Y, L, K$. These measurable quantities relate, under the stated conditions, to the profit function as $s_{Y}=\partial \ln \Pi / \partial \ln p_{Y}$, $-s_{I}=\partial \ln \Pi / \partial \ln p_{I}$ for $I=L, K$. Moreover, we have $s_{Y}-s_{L}-s_{K}=1$. Defining $s_{G}=\partial \ln \Pi / \partial \ln G$ and $s_{t}=\partial \ln \Pi / \partial \ln t$, equation (3) is restated as:

$$
\frac{d(Y / L)}{Y / L}=\frac{s_{K}}{s_{Y}}\left(\frac{d K}{K}-\frac{d L}{L}\right)-\frac{1}{s_{Y}} \frac{d L}{L}+\frac{s_{G}}{s_{Y}} \frac{d G}{G}+\frac{s_{t}}{s_{Y}} d t
$$

We specify a translog function, again without $[\ln G]^{2}$ and $t[\ln G]$. From this, we derive equations for $s_{Y}$ and $-s_{L}$. In particular, the profit function is written as:

$$
\ln \Pi=\gamma_{0}+\gamma^{\prime} z+0.5 z^{\prime} \Delta z
$$

where $z^{\prime}=\left(\ln p_{Y}, \ln w, \ln p_{K}, \ln G, t\right), \gamma^{\prime}=\left(\gamma_{Y}, \gamma_{L}, 1-\gamma_{Y}-\gamma_{L}, \gamma_{G}, \gamma_{t}\right)$, and

$$
\Delta=\left(\begin{array}{ccccc}
\delta_{Y Y} & \delta_{Y L} & -\delta_{Y Y}-\delta_{Y L} & \delta_{Y G} & \delta_{Y t} \\
\delta_{Y L} & \delta_{L L} & -\delta_{Y L}-\delta_{L L} & \delta_{L G} & \delta_{L t} \\
-\delta_{Y Y}-\delta_{Y L} & -\delta_{Y L}-\delta_{L L} & \delta_{Y Y}+\delta_{L L} & -\delta_{Y G}-\delta_{L G} & -\delta_{Y t}-\delta_{L t} \\
\delta_{Y G} & \delta_{L G} & -\delta_{Y G}-\delta_{L G} & 0 & 0 \\
\delta_{Y t} & \delta_{L t} & -\delta_{Y t}-\delta_{L t} & 0 & \delta_{t t}
\end{array}\right)
$$

The share equations are then specified using parameters from $\gamma$ and $\Delta$ above:

$$
\begin{gathered}
s_{Y}=\gamma_{Y}+\Delta_{Y} z \\
-s_{L}=\gamma_{L}+\Delta_{L} z
\end{gathered}
$$

where $\Delta_{Y}$ and $\Delta_{L}$ are the first and second rows of matrix $\Delta$.

Once again, assuming additive disturbance terms, we estimate the $\ln \Pi-, s_{Y}-$ and $\left(-s_{L}\right)-$ equations, (11), (12) and (13), jointly with the cross-equation parameter restrictions imposed. 


\section{IV.3 Exploiting the Information in Panel Data}

The cost and profit function models specified above are estimated with panel data, consisting of 30 provinces over seven time periods. Denote the disturbance terms in the three equations as $u_{j i t}$ for $j=1,2,3$; and let $u_{i t}=\left(u_{1 i t}, u_{2 i t}, u_{3 i t}\right)^{\prime}$. It is assumed that $E\left[u_{i t}\right]=0$ and $\operatorname{Var}\left(u_{i t}\right)=\Sigma=\left\{\sigma_{j k}\right\}$, a full $3 \times 3$ covariance matrix. Note that we actually estimate the correlation parameters of the matrix $\Sigma$ rather than the covariances.

Given rigidities in the economy, one would quite well expect some degree of serial correlation over time. Similarly, given shared economic environments, one should not be surprised to find correlation among provinces. The question is how to model these correlations efficiently. Consider, for example, the correlation between $u_{i t}$ and $u_{i, t-1}$ : in principle, $\operatorname{corr}\left(u_{i t}, u_{i, t-1}\right)$ contains nine serial correlation parameters. The adding-up constraint on the share equations restricts the serial correlation coefficient of these share equations to be the same (Berndt and Savin, 1975), but that would still leave many parameters to be estimated. In the same way, one could spend many parameters on a model of correlation among provinces. In this paper, we use a highly parsimonious specification of correlation patterns. Given that the data span only seven years, we only incorporate a single time-correlation coefficient $\rho$ in our model. Define $\mathrm{P}_{1}$ as a $7 \times 7$ matrix:

$$
\mathrm{P}_{1}=\left\{\rho_{i j}\right\} \text { where } \rho_{i j}=\rho^{|i-j|}, i, j=1, \ldots, 7
$$

This is the familiar correlation matrix of a disturbance that has an AR(1) serial correlation structure. As the estimation results later on will show, the estimate of $\rho$ is quite large, meaning that if, for example, a disturbance of a given equation in a given province is positive in one year, it tends to come out positive in other 
years as well. An alternative way to capture this same data feature is by specifying a province-level random effect, through the correlation matrix:

$$
\mathrm{P}_{2}=\left\{\rho_{i j}\right\} \text { where } \rho_{i j}=1 \text { if } i=j \text { and } \rho_{i j}=\rho \text { otherwise }
$$

In this case, $\rho$ measures the proportion of the variance of a disturbance that is due to the province random effect.

The province correlation structure must incorporate information about province borders. The easiest specification is the following:

$$
\Theta_{1}=I_{30}+\theta N_{1}
$$

where $I_{30}$ is an identity matrix of order 30 , and $N_{1}=\left\{N_{1, i j}\right\}$ is a $30 \times 30$ matrix indicating which provinces share a border: if $n_{1 i}$ is the number of provinces that border with province $i$, then $N_{1, i j}=1 / n_{1 i}$ if $i$ and $j$ are neighbors, and $=0$ if not; moreover, $N_{1, i i}=0 .^{7}$ Thus, $\Theta_{1}$ provides for correlation between neighboring provinces.

While this is somewhat in the spirit of the usual concept of serial correlation, $\Theta_{1}$ implies absence of correlation between non-neighboring provinces $i$ and $k$ even when both have a border with $j$. This is remedied when the correlation matrix is specified as:

$$
\Theta_{2}=I_{30}+\theta N_{1}+\theta^{2} N_{2}
$$

where the elements of $N_{2}$ equal 1 (prior to row-standardization) if the province pair shares a common neighbor, and equal 0 otherwise. These specifications are illustrated in Figure 2 for the case of the province

7 The rows of $N_{1}$ sum to 1: thus, $N_{1}$ is row-standardized. This is proper, since the number of neighboring provinces vary across provinces. If $N_{1}$ would not be row-standardized, the neighboring correlation effects would be stronger for provinces with more neighbors, contrary to the spirit of the serial correlation of spatial units. See also Anselin and Bera (1998). Similarly, the matrix $N_{2}$ below is row-standardized. 
of Jiangxi. In matrix $N_{1}$, in the row (and column) that represents Jiangxi, the elements in the columns (and rows) for Guangdong, Fujian, Zhejiang, Anhui, Hubei, and Hunan are nonzero: these provinces form the first circle around Jiangxi. In matrix $N_{2}$, in the row (and column) that represents Jiangxi, we list those provinces in the second circle around Jiangxi, i.e., Hainan, Guangxi, Guizhou, etc.

Apart from $\Theta_{1}$ and $\Theta_{2}$, we examine a third inter-province correlation structure in $\Theta_{3}$, which allows correlation among each and every province:

$$
\Theta_{3}=\left\{\theta_{i j}\right\} \text { where } \theta_{i j}=1 \text { if } i=j, \text { and } \theta_{i j}=\theta \text { otherwise }
$$

Note that, in effect, $\Theta_{3}$ is consistent with a random effect for time, where $\theta$ would indicate the proportion of the variance of a disturbance that is due to the time random effect. Under this structure, it is indeed the common time factor, owing to a common business cycle or a joint policy environment, that creates a correlation among provinces. $^{8}$

To complete the specification of the correlation structure, let $u_{t}$ be constructed by stacking the vectors $u_{i t}$, and let $u$ stack $u_{t}$. Then

$$
\operatorname{Var}(u)=\Theta \otimes \mathrm{P} \otimes \Sigma
$$

for the alternative specifications of $\Theta$ and $\mathrm{P}$. This implies that the correlation structure is modeled in multiplicative rather than the usual additive form. For example, the covariance between $u_{1 i t}$ and $u_{2 i s}$ equals $\sigma_{12} \mathrm{P}_{t s} \Theta_{i j}$, implying that, e.g., the covariance between $u_{1 i t}$ and $u_{2 i t}$ is larger than that between $u_{1 i t}$ and $u_{2 i s}$ (over time) or between $u_{1 i t}$ and $u_{2 j t}$ (among provinces), both of which are larger than the covariance they examine sectoral price movements. 
between $u_{1 i t}$ and $u_{2 j s}$ (different province, different time).

All parameters are estimated simultaneously by means of maximum likelihood methods. As noted above, some elements of the model are consistent with a random effects specification. We do not test for the validity of this relative to an alternative fixed effects specification, which is intractable in these models. However, the evidence in Section III provides a minimal statistical justification for our random effects specification here.

\section{Estimation Results}

As there are a number of alternative correlation structures, we shall first compare the various models in Table 3. The top panel shows that there clearly are cross-time and cross-province correlation patterns in the cost function model. The values of $\rho$ and $\theta$ are both large and significant; the $t$-statistics are quite similar across the various specifications. Although the specifications are not nested, it seems right to focus on those that contain either $\left(\mathrm{P}_{1}, \Theta_{3}\right)$ or $\left(\mathrm{P}_{2}, \Theta_{3}\right)$, because the log-likelihood value is substantially higher. As for the profit function model, it is certainly necessary to include a time series correlation factor, but the data do not distinguish strongly among the alternative province correlation structures. Once again, and partly for reason of symmetry, we choose the specifications with $\left(\mathrm{P}_{1}, \Theta_{3}\right)$ and $\left(\mathrm{P}_{2}, \Theta_{3}\right)$, as these yield the highest log-likelihood value.

Table 4 presents the complete set of estimates of the cost and profit function models for both of these specifications. Consider the cost function model, and let us focus on the specification with $\left(\mathrm{P}_{1}, \Theta_{3}\right)$. According to equation (6), the cost of production depends on $G$ as follows: 


$$
\ln \hat{C}=\ldots+0.620 \ln G-0.032\left(\ln w-\ln p_{K}\right) \ln G-0.070 \ln Y \ln G
$$

At the sample averages of $\ln w=-0.438, \ln p_{K}=-2.166$, and $\ln Y=5.6364$, this expression reduces to $\ln \hat{C}=\ldots+0.309 \ln G$. That is, for a typical province in a typical year, a greater provision of public capital raises the cost of production among enterprises with independent accounting systems. As for the labor share equation, the estimated parameters imply that $\hat{\sigma}_{L}=\ldots-0.032 \ln G$. In other words, rising levels of public capital lower the cost share of labor and raise the cost share of capital (though the effect is significant only at the 11 percent level), though the effect is small enough that labor cost rises with $G .^{9}$ Furthermore, since $\hat{\sigma}_{Y}=\ldots-0.070 \ln G$, the ratio of the value of output to cost falls with increasing quantities of public capital, but output itself rises with $G .{ }^{10}$ The parameter estimates in the specification with $\left(\mathrm{P}_{2}, \Theta_{3}\right)$ are smaller, and each of the relationships with $G$ is weaker (e.g., $\ln \hat{C}=\ldots+0.083 \ln G$ ), but the signs of the individual parameter estimates are the same. Overall, the conclusion with the two specifications is the same: it appears that public capital impacts productive activity but raises costs more than output.

All of this contrasts with the estimates of the profit function. The specification with $\left(\mathrm{P}_{1}, \Theta_{3}\right)$ indicates that:

$$
\ln \hat{\Pi}=\ldots+1.711 \ln G-0.177\left(\ln p_{Y}-\ln p_{K}\right) \ln G+0.119\left(\ln w-\ln p_{K}\right) \ln G
$$

which at the sample average simplifies to $\ln \hat{\Pi}=\ldots+0.536 \ln G$. Thus, profits rise with the provision of

\footnotetext{
9 Since $\sigma_{L}=w L / C$, we have $\Delta \sigma_{L}=\sigma_{L}(\Delta \ln (w L)-\Delta \ln C)$. Thus, given the sample average of $\sigma_{L}=0.50$, we find $\Delta \ln (w L)=\left(1 / \sigma_{L}\right) \Delta \sigma_{L}+\Delta \ln C=\ldots+0.217 \ln G$.

10 With an average of $\sigma_{Y}=2.41$, it follows that $\Delta \ln \left(p_{Y} Y\right)=\ldots+0.252 \ln G$.
} 
public capital. Moreover, $\hat{s}_{Y}=\ldots-0.177 \ln G \quad$ and $\quad \hat{s}_{L}=\ldots-0.119 \ln G ; \quad$ thus $\hat{s}_{K}=\hat{s}_{Y}-\hat{s}_{L}-1=\ldots-0.058 \ln G$. This implies that the ratio of output over profits, labor expenses over profit, and capital costs over profits all fall with public capital: profits rise faster with $G$ than each numerator, but it turns out that output and labor cost still rise with $G$ in magnitudes that are similar to the cost function results. ${ }^{11}$ For the $\left(\mathrm{P}_{2}, \Theta_{3}\right)$ specification, the relationships we estimate are all much weaker; e.g., $\ln \hat{\Pi}=\ldots+0.074 \ln G$.

Another perspective on the impact of public capital is obtained by examining the decomposition of labor productivity growth along the lines of equation (3). This is done for each year in Table 5, averaging across provinces. Using the cost function approach, we find that productivity rises because of $(a)$ growthin the capital labor ratio, and $(b)$ a secular time trend that captures technological growth, a changing market structure, the shifting political environment, and so on. For example, in 1995-96, labor productivity was predicted to rise by 12.2 percent, with 7.7 percent coming from the increase in $K / L$ and 5.4 percent from the secular time trend. The decomposition confirms the inference above that public capital lowers, or otherwise is unrelated to, productivity. Surprisingly, the decline in the labor force has a negative impact on labor productivity, suggesting according to equation (2) that the industry sector operates at increasing returns to scale. Overall, the cost function models track, but not at all closely, the observed variation over time in labor productivity growth.

The decomposition on basis of the profit function estimates shows different patterns. Here, public capital is the most important factor generating labor productivity growth. Moreover, the 1997-98 plunge in

11 With $s_{L}=0.544$ and $s_{Y}=2.236$, we find $\Delta \ln (w L)=\ldots+0.317 \ln G$ and $\Delta \ln \left(p_{Y} Y\right)=\ldots+0.457 \ln G$. 
employment was associated with a sharp rise in labor productivity; as shown in Section IV, the sensitivity of labor productivity growth to changes in employment suggests decreasing returns to scale in industrial production. Growth in $K / L$ has a smaller impact, and the time trend puts a damper on productivity growth.

Thus, the cost and profit function models differ in their explanation of productivity growth over time. How do they compare when we examine productivity by province? Table 6 divides the 30 provinces in three groups according to their initial level of labor productivity and aggregates growth rates over time. We find that the cost model, which does not track the variation in labor productivity growth over time well, provides a better explanation of province-level differences in labor productivity growth than the profit model: the correlation between observed and predicted labor productivity growth is around 0.58 for the cost model and around 0.28 for the profit model. Moreover, it appears that the provinces with the highest initial labor productivity experienced the highest growth, a fact that is picked up by the cost model but not the profit model.

It becomes clear that the cost and profit function model paint two very different pictures of the structure of production in the private sector (firms with independent accounting systems) in China. ${ }^{12}$ How is one to choose from these two pictures? Let us return to Table 4. The log-likelihood value of the profit function models is much lower than that of the cost function model, even though the basic structure of the model is the same: both contain two share equations and one log-value equation. Thus, the fit of the profit

12 One other aspect of comparison is found in the estimates of Dand 2. For both models, Dis large. The estimate of $D_{2}$ suggests that more than 80 percent of the variance in the disturbances derives from provincial factors that stay constant over time. On the other hand, $2_{3}$ is estimated at 0.50 for the cost function model, suggesting that half of the variance in the disturbances results from factors common to all provinces at a point of time, as opposed to less than 0.10 for the profit function model. The latter might also be interpreted as evidence of random noise dominating the dependent variables of 
function model appears poorer. More evidence of this is found in the covariance structure of these three equations. The log-value equations contain disturbances of roughly the same magnitude: the variances are $\sigma_{C C}=0.167$ and $\sigma_{\Pi \Pi}=0.463$, focusing on the specifications with $\left(\mathrm{P}_{1}, \Theta_{3}\right)$ for the sake of convenience. The labor/cost equation has a tight fit $\left(\sigma_{L L}=0.016\right)$ and the output/cost share is noisier $\left(\sigma_{Y Y}=2.733\right)$, but in the profit model the labor/profit ratio is noisy $\left(\sigma_{L L}=2.417\right)^{13}$ and the output/profit ratio appears nearly impossible to fit $\left(\sigma_{Y Y}=24.804\right)$. In addition, the correlation between the disturbances of the labor/profit and output/profit ratios equals - 0.991 , implying that these two ratios frequently move in opposite directions for reasons unrelated to the explanatory variables in the model. Altogether, this suggests that output (and thereby profit) apparently is the noisiest component in the whole model. This supports the argument that output is subject to large extraneous macroeconomic shocks and inputs (labor and capital) adjust only slowly, which jibes with the discussion of China's economy in Section II.2. This also casts doubts on the validity of the profit function model and leaves us with the results derived from the cost function model.

\section{Conclusion and Discussion}

This paper examines the hypothesis that public capital impacts productivity in the industrial sector with data describing 30 provinces, autonomous areas, and municipalities in China from 1994 to 2000. The

evidence that is presented is twofold. A simple regression model that explores the reasons behind the variations in labor productivity across provinces over time suggests a strong positive role for the provision of public capital in China, as has indeed been found in various places around the world. However, this result is

the profit function model.

13 The implied standard deviation equals 1.55: a typical variation of the labor/profit ratio equals 155 percentage points. 
based on an empirical model where several of the control variables are generally considered to be simultaneously determined, at least in the context of a market economy. Alternative models based on duality theory overcome this econometric problem. From these models, one can extract estimates of the contribution of public capital to labor productivity in the industrial sector that would be free from simultaneity bias. Indeed, these cost and profit function models are standard tools and are often applied.

In the context of China, we find that the profit function model assigns an important role to public capital in the determination of labor productivity growth. Moreover, it predicts variations in labor productivity growth over time fairly well, though it fails to distinguish adequately among provinces. However, its fit appears poor, for reasons that are traced to probable noise in the measurement of output. Note that if one dismisses the profit function results on grounds of noisy output data, one must also reject the outcomes of the labor productivity regression model of productivity growth. The cost function model appears to fit much better and tracks variations in productivity growth among provinces quite well, but is less precise on the prediction of the aggregate movements of labor productivity over time. It also indicates that public capital does not contribute to growth in labor productivity, in contrast with the results obtained from profit function model and from the simple labor productivity regression model.

One may want to question these results on various grounds. First, the cost and profit function approaches are based on economic principles that apply in industrial countries but perhaps not in China. It is an accepted fact that, historically, state-owned enterprises existed not only to generate production but also to provide employment, a living wage, and health care and education to the Chinese population. Thus, these enterprises could be viewed as having an objective function that included the volume of output and the wellbeing of its workers. However, China is undergoing a rapid transformation towards a market-driven 
economy ever since the early 1980s. The enterprises modeled here are ones with independent accounting systems and therefore more intensely subject to market forces than before. Moreover, even if factory managers would not make decisions on the basis of economic (profit-maximizing) principles, someone in the chain of command should care about labor productivity and efficient allocation of resources, probably more so in recent years than a few decades ago. Thus, it is not clear that the cost and profit function approaches would not apply at least approximately.

Second, the quality of the data is not optimal. Our measure of public capital is at most a proxy for the value and quality of infrastructure that we would like it to represent. The production, wage, capital, and capital cost data are, for that matter, proxies as well, subject to measurement error and to definitional inconsistencies over time and across provinces. The diminishing role of the SOEs in the overall economy implies a change in the "economic agent" over time and therefore also in the nature of the underlying production process. The labor data describe a slightly different segment of the industrial sector than the output and capital data. Nevertheless, the data are the best ones available. They are obtained from official publications and, on that account, are as reliable as one may hope them to be.

Third, the cost and profit function models contain a smooth time trend, as is common in most research in this field. However, the labor productivity regression model allows the time trend to be variable, and both the regression results and the overview of the macroeconomic conditions in China indicate that the trend is hardly smooth. Should the cost and profit function models be more elaborately specified with a varying rather than smooth time trend? To modify these models requires five parameters to be added to 
each equation, which renders the models substantially more difficult to estimate. ${ }^{14}$ But practically speaking, this time trend stands for the collection of secular changes that are taking place in China over these few years. Even if it is found that the trend effects on labor productivity, costs, and profits are so large and so variable, the question is still open as to what exactly it represents. Specifying a smooth time trend aims to measure long run trend effects, and as the summary tables indicate, this long run trend is allowed to change smoothly over time. Thus, our model specification does not interfere with the primary research question, which is whether public capital matters. Our conclusion is that the short run contribution of public capital to labor productivity is likely non-existing or even negative but that the long run contribution is substantial. Future research should focus on firming up these conclusions and also on finding other explanations for the variation in labor productivity growth over time and between provinces.

\section{Appendix: Data Sources}

The data are gathered from various issues of the China Statistical Yearbook and refer to the years 1994-2000. In particular we define the following variables (where the references in the square brackets refer to the volume and page numbers of the respective issues of the China Statistical Yearbook):

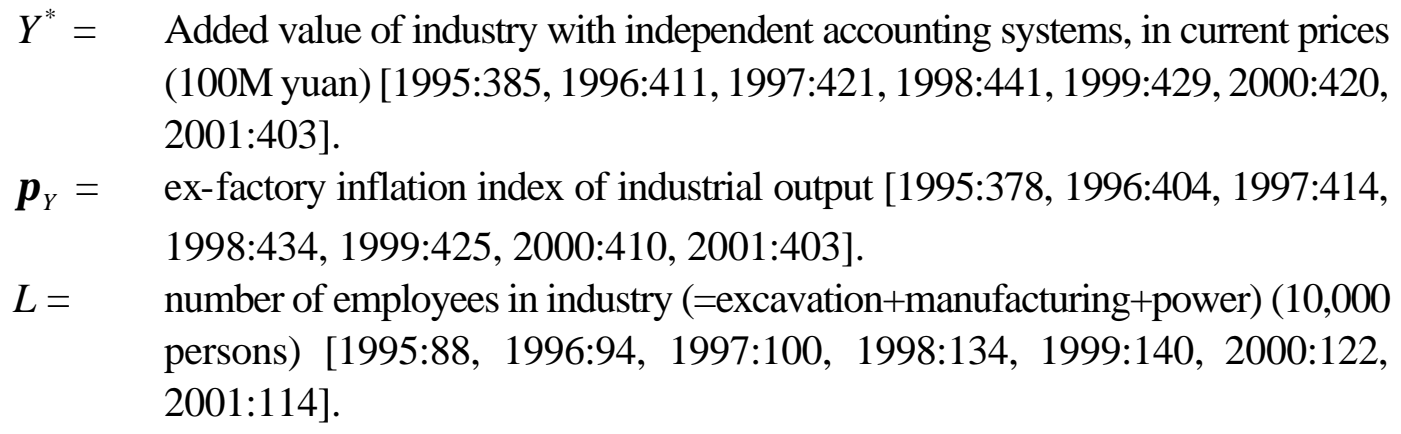

14 Each of the five time dummy parameters in each share equation must appear in interactions with price variables in the cost and profit equations for the models to be internally consistent. See equations (6) and (11). 
$B=\quad$ Wage bill in industry (=excavation+manufacturing+power), current price (10M yuan) $[1995: 110,1996: 118,1997: 124,1998: 160,1999: 158,2000: 142$, 2001:136].

$K^{*}=$ Average net value of fixed assets among industrial enterprises with independent accounting system, current prices (100M yuan) [1995:386, 1996:412, 1997:422, 1998:442, 1999:430, 2000:421, 2001:417].

$I_{G}^{*}=\quad$ Newly increased fixed assets of (i.e., investment in) transportation, storage, posts, and telecommunications, current prices (100M yuan) [1994:155,163; 1995:151,167; 1996:153,169; 1997:165,181; 1998:201,217; 1999:199,213, 2000:183,201; 2001:173,190].

$\pi_{I M P}=$ Ex-factory inflation index of means of industrial production, used as the inflation index of investments in fixed assets prior to 1993 [1994:248]

$\pi_{I F A}=$ Inflation index of investment in fixed assets, available from 1993 onward [1995:250, 1996:272, 1997:283, 1998:318, 1999:310, 2000:306, 2001:298].

$d=\quad$ depreciation rate, equals 4.5 percent for all years (by assumption)

$r=\quad$ interest rate on one-year investment loans for fixed assets, equals 10.98 percent for 1994,1995 ; 10.81 percent for 1996; 9.78 percent for $1997 ; 7.55$ percent for 1998; 5.97 percent for 1999; and 5.72 percent for 2000 [1998:672; 2001:641]. As the interest rate varies during the year, $r$ is computed by weighted average to reflect calendar years.

Several variables are derived from this information:

$$
\begin{array}{ll}
p_{L}= & \text { Average wage per employee industry }(10000 \text { yuan })=B / L . \\
p_{Y}= & \text { price index of industrial output, }=\pi_{Y}(t) \times p_{Y}(t-1) / 100 \text { for } 1994, \ldots, 2000 ; \\
& p_{Y}(1993)=1 . \\
q_{K}=\quad \text { price index of investment in fixed assets }=\pi_{I F A}(t) \times q_{K}(t-1) / 100 \text { for } 1994, \ldots, & 2000 ; q_{K}(1993)=1 . \\
p_{K}=\quad \text { user cost of capital, computed as }(d(t)+r(t)) q_{K}(t)-\left(q_{K}(t)-q_{K}(t-1)\right)
\end{array}
$$

The index $q_{K}$ is used to deflate both $K^{*}$ and $I_{G}^{*} \cdot Y^{*}$ is deflated with the index $p_{Y}$. Thus:

$$
\begin{array}{ll}
Y= & Y^{*} / p_{Y} \\
K= & K^{*} / q_{K} \\
I_{G}= & I_{G}^{*} / q_{K}
\end{array}
$$

Since $K$ refers to the capital stock at the end of the calendar year and the production process summarizes the activity during the calendar year, the capital stock value used in the empirical analysis equals 
the average of $K$ of the current and previous calendar year.

We are forced to work with public capital investment information because the publication of data on the stock of public infrastructure data ceased after 1998. From the public capital investments $\left(I_{G}\right)$, we compute the stock of public capital $G$ by means of the perpetual inventory method (e.g., Katz and Herman, 1997), using the depreciation rate $d$ to find the current quantity of each vintage of $I_{G}(t)$ for $t=1985, \ldots$, 2000. To account for public capital investments prior to 1985 , for which data are not available, we assume that investments grew by 15 percent per year up to 1985 . Once again, we note that we derive mid-year stock values of $G$ in order to be consistent with the productive process.

It should be noted that $\pi_{I F A}$ is available for each province only since 1993 . Prior to this year, the best price index available to deflate nominal investment values $I_{G}^{*}$ is $\pi_{I M P}$, which is measured nationally.

Finally, the empirical models utilize a standardized time trend variable:

$$
t=\mathrm{YEAR}-1994
$$

or a set of time dummy variables that treat 1994 as the omitted category.

\section{References}

Anselin, Luc, and Anil K. Bera. "Spatial Dependence in Linear Regression Models with an Introduction to Spatial Econometrics." In Amman Ullah and David Giles, eds., Handbook of Applied Economic Statistics. New York: Marcel Dekker, 1998, 237-289.

Aschauer, David A. “Is Public Expenditure Productive?” Journal of Monetary Economics. 23 (1989) 177-200.

Aschauer, David A. “Is Government Spending Stimulative?” Contemporary Policy Issues. 8:4 (Oct. 1990), 30-46.

Barro, Robert J. "Government Spending in a Simple Model of Endogenous Growth." Journal of Political Economy. 98:5 (October 1990), S103-S125.

Berndt, Ernst R., and Bengt Hansson. "Measuring the Contribution of Public Infrastructure Capital in Sweden." Scandinavian Journal of Economics. 94:Suppl. (1992), 151-168. 
Berndt, Ernst R., and N. Eugene Savin. "Estimation and Hypothesis Testing in Singular Equation Systems with Autoregressive Disturbances." Econometrica, 43:5 (Sept. 1975), 937-957.

Boisso, D., S. Grosskopf, K. Hayes. "Productivity and Efficiency in the US: Effects of Business Cycles and Public Capital," Regional Science and Urban Economics, 30 (2000), 663-681.

Chow, Gregory C. China’s Economic Transformation. Oxford: Blackwell Publ., 2003.

Costa, Jose da Silva, Richard W. Ellson, and Randolph C. Martin. "Public Capital, Regional Output, and Development: Some Empirical Evidence.” Journal of Regional Science, 27 (Aug. 1987), 419-437.

Conrad, Klaus, and Helmut Seitz. "The Economic Benefits of Public Infrastructure." Applied Economics, 26:4 (April 1994) 303-311.

Demetriades, Panicos, and Theofanis Mamuneas. "Intertemporal Output and Employment Effects of Public Infrastructure Capital: Evidence from 12 OECD Economies.” Economic Journal, 100:465 (July 2000), 687-712.

Demurger, Sylvie. "Infrastructure Development and Economic Growth: An Explanation for Regional Disparities in China?" Journal of Comparative Economics, 29 (March 2001), 95-117.

Deno, Kevin T. "The Effect of Public Capital on U.S. Manufacturing: 1970 to 1978." Southern Economic Journal, 55:3 (October 1988) 400-411.

Dickinson, David. "Monetary Policy and Structural Changes in the Financial Sector in China." In P.W. Preston and Jürgen Haacke, Contemporary China: The Dynamics of Change at the Start of the New Millennium. London: RoutledgeCurzon, 2003, 25-44.

Garcia-Mila, Teresa and Therese J. McGuire. "The Contribution of Publicly Provided Inputs to States' Economies.” Regional Science and Urban Economics, 22:2 (February 1992) 229-241.

Garcia-Mila, Teresa, Therese J. McGuire, and Robert H. Porter. "The Effect of Public Capital in State-Level Production Functions Reconsidered." Review of Economics and Statistics, 75:1 (February 1996) 177180.

Gramlich, Edward M. "Infrastructure Investment: A Review Article." Journal of Economic Literature, 32:3 (September 1994), 1176-1196.

Holtz-Eakin, Douglas. "Public-Sector Capital and the Productivity Puzzle." Review of Economics and Statistics, 76:1 (February 1994), 12-21.

Hughes, Neil C. China's Economic Challenge: Smashing the Iron Rice Bowl. Armonk, N.Y.: M.E. Sharpe, Inc., 2002.

Hulten, Charles R., and George E. Peterson. "The Public Capital Stock: Needs, Trends and Performance." American Economic Review, 74:2 (May 1984), 166-173.

Katz, Arnold J., and Shelby W. Herman. "Improved Estimates of Fixed Reproducible Tangible Wealth, 19291995." Survey of Current Business. 77 (May 1997) 69-76.

Kemmerling, Achim, and Andreas Stephan. "The Contribution of Local Public Infrastructure to Private 
Productivity and its Political Economy: Evidence from a Panel of Large German Cities." Public Choice. 113:3-4 (December 1992), 403-424

Kim, S., J. Koo and Y. H. Lee. "Infrastructure and Production Efficiency: An Analysis on the Korean Manufacturing Industry." Contemporary Economic Policy, 17:3 (1999), 390-400.

Lin, Justin Yifu, Fang Cai and Zhou Li. The China Miracle: Development Strategy and Economic Reform. HongKong: The Chinese University Press, 1996.

Lynde, Catherine, and James Richmond. "Public Capital and Total Factor Productivity." International Economic Review. 34:2 (May 1993) 401-414.

Mas M., J. Maudos, F. Perez, and E. Uriel. "Infrastructures and Productivity in the Spanish Regions." Regional Studies, 30:7 (November 1996), 641-649.

Mead, J.E.. "External Economies and Diseconomies in a Competitive Situation.” Economic Journal, 62 (March 1952), 54-67.

Mitra, Arup, Aristomene Varoudakis, Marie-Ange Veganzones-Varoudakis. "Productivity and Technical Efficiency in Indian States' Manufacturing: The Role of Infrastructure." Economic Development and Culture Change, 50:2 (January 2002), 395-418.

Moreno, Rosina, Enrique Lopez-Bazo, and Manuel Artis. "Public Infrastructure and the Performance of Manufacturing Industries: Short- and Long-Run Effects." Regional Science and Urban Economics, 32:1 (January 2002) 97-121.

Moreno, Rosina, Enrique Lopez-Bazo, Esther Vaya, and Manuel Artis. "Externalities, Public Capital, and Costs of Production.” University of Barcelona, 1998.

Morrison, Catherine J., and Amy E. Schwartz. "State Infrastructure and Productive Performance." American Economic Review, 86:5 (December 1996) 1095-1111.

Munnell, Alicia H. "Why Has Productivity Growth Declined? Productivity and Public Investment." New England Economic Review. (Jan/Feb 1990) 3-22 (a).

Munnell, Alicia H. "How does Public Infrastructure Affect Regional Economic Performance?" New England Economic Review. (Sept/Oct 1990) 11-32 (b).

Munnell, Alicia H. 'Policy Watch: Infrastructure Investment and Economic Growth." Journal of Economic Perspective, 6 (Fall 1992), 189-198.

Preston, P.W., and Xing Aifen. "State-Owned Enterprises: A Review of Development Dynamics, Contemporary Problems and the Shape of the Future." In P.W. Preston and Jürgen Haacke, Contemporary China: The Dynamics of Change at the Start of the New Millennium. London: RoutledgeCurzon, 2003, 73-88.

Rovolis, Antonis, and Nigel Spence. "Duality Theory and Cost Function Analysis in a Regional Context: The Impact of Public Infrastructure Capital in the Greek Regions." Annals of Regional Science. 36:1 (February 2002), 55-78.

Shah, Anwar. "Dynamics of Public Infrastructure, Industrial Productivity and Profitability." Review of Economics and Statistics, 74:1 (February 1992), 28-36. 
Strum, J.E., Jacobs, J. and P. Groote. "Output Effects of Infrastructure Investment in the Netherlands, 18531913.” Journal of Macroeconomics, 21:2 (Spring 1999), 355-380.

Vijverberg, Chu-Ping C., and Wim P.M. Vijverberg. "Diagnosing the Productivity Effect of Public Capital in the Private Sector." University of Texas at Dallas, 2003.

Vijverberg, Wim P.M., Chu-Ping C. Vijverberg, and Janet L. Gamble. "Public Capital and Private Productivity." Review of Economics and Statistics. 79:2 (May 1997), 267-278.

Wang, Eric C. "Public infrastructure and economic growth: a new approach applied to East Asian economies." Journal of Policy Modeling. 24:5 (August 2002), 411-435.

Wei, Shang-Jin. "Is Globalization Good for the Poor in China?" Finance \& Development, 39:3 (September 2002), 26-29.

Wei, Shang-Jin, and Yi Wu. "Globalization and Inequality: Evidence from within China." NBER Working Paper 8611, November 2001.

Wylie, Peter J. "Infrastructure and Canadian Economic Growth 1946-1991." Canadian Economic Review. 29:Supp (April 1996), S350-S355.

$\mathrm{Xu}$, Xinpeng, and J.P. Voon. "Regional Integration in China: A Statistical Model." Economics Letters. 79:1 (January 2003), 35-42. 
Figure 1: Trends in Labor Productivity in China's Provinces

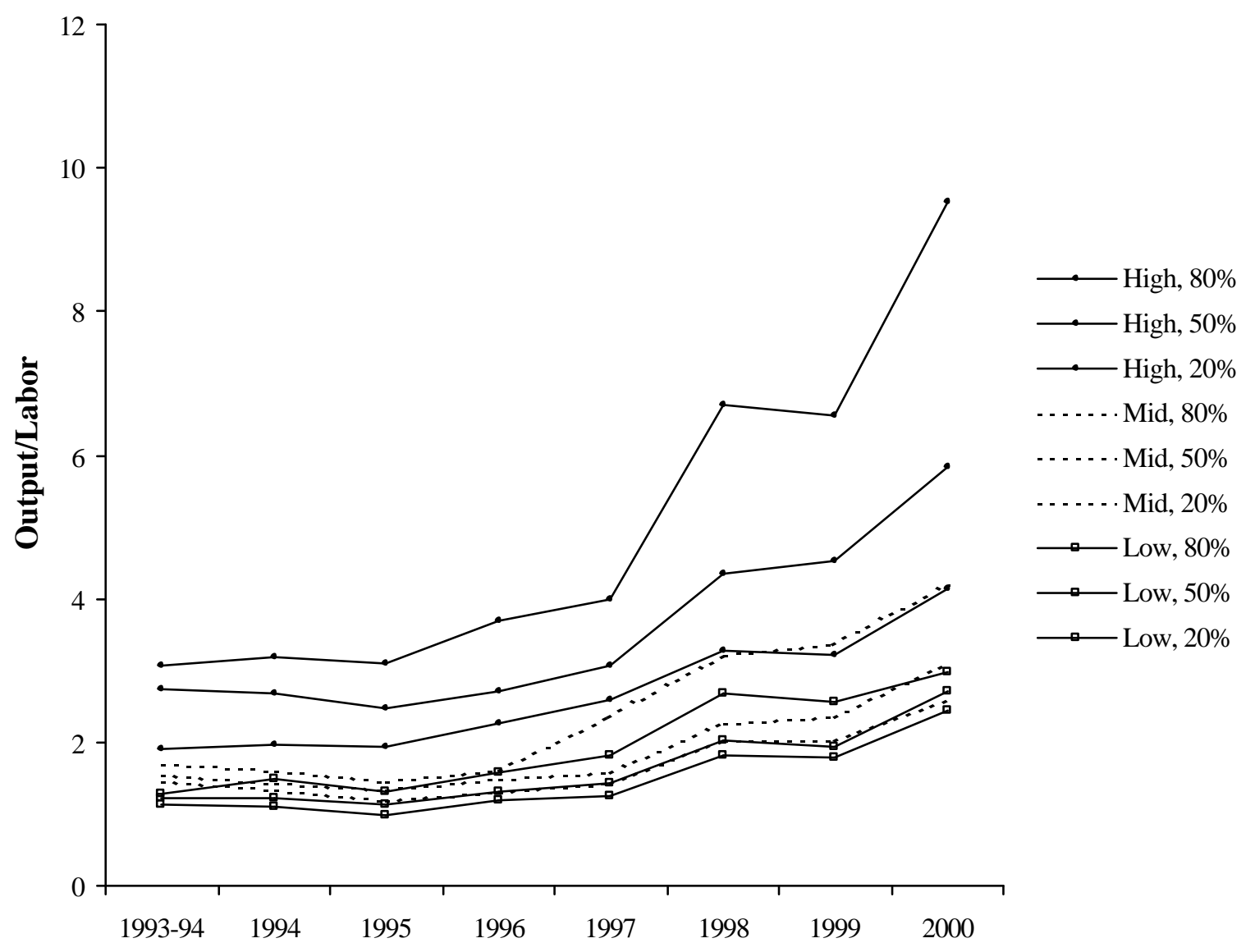


Figure 2: Illustrating Spatial Correlation Relative to the Province of Jiangxi

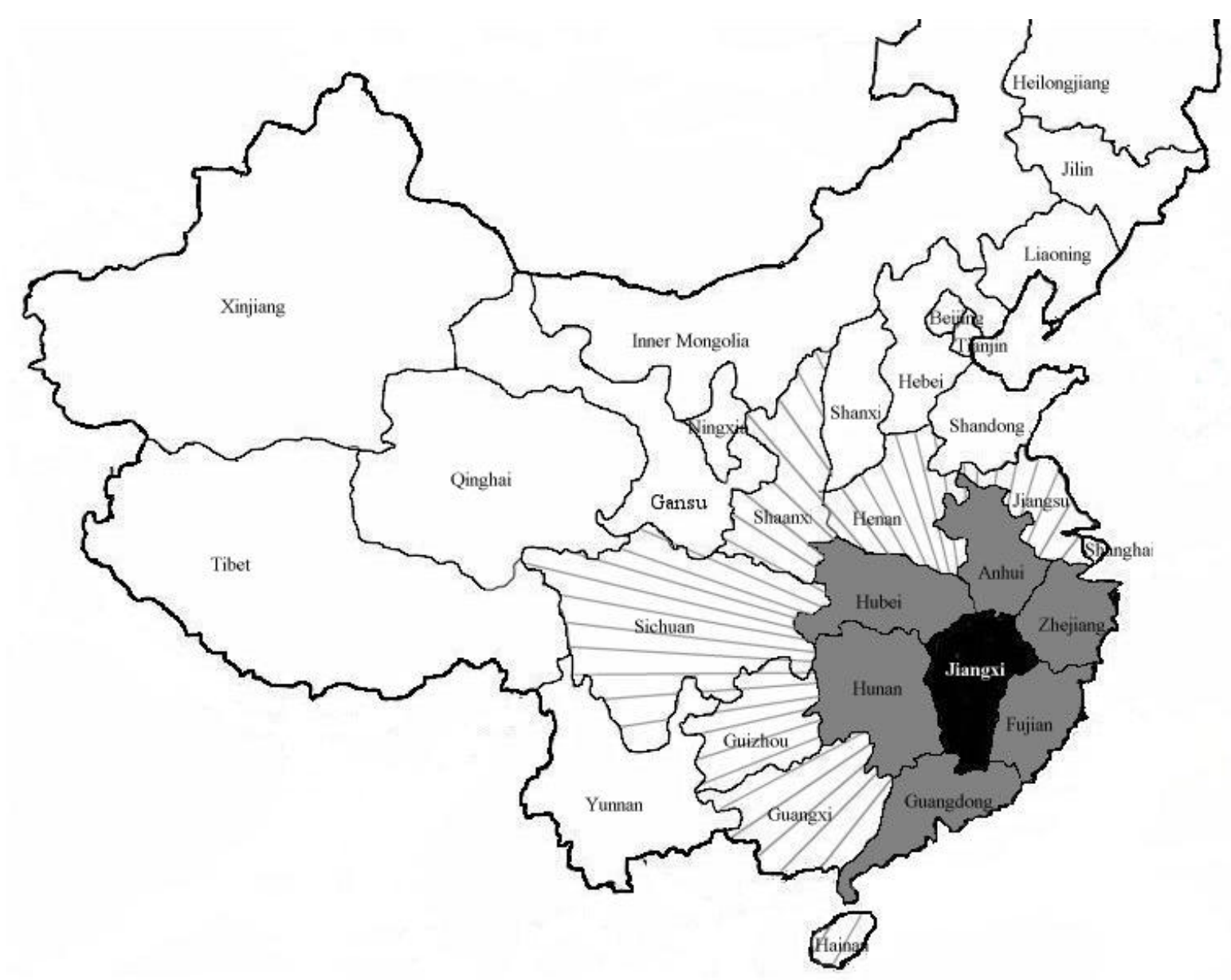


32

Table 1: Trends in Labor Productivity, Capital Intensity, and Provision of Public Capital ${ }^{a}$

\begin{tabular}{lrrrrrrrr} 
& 1993 & 1994 & 1995 & 1996 & 1997 & 1998 & 1999 & 2000 \\
\hline Output/Labor $^{\mathrm{b}}$ & 1.81 & 1.79 & 1.66 & 1.92 & 2.21 & 3.17 & 3.15 & 4.22 \\
Capital/Labor $^{\mathrm{b}}$ & n.a. & 2.81 & 3.32 & 4.18 & 5.10 & 7.31 & 8.66 & 10.37 \\
Public Capital $^{\mathrm{c}}$ & 140 & 158 & 185 & 218 & 258 & 309 & 369 & 442 \\
Labor $^{\mathrm{d}}$ & 214 & 219 & 220 & 215 & 207 & 158 & 147 & 137 \\
\hline
\end{tabular}

${ }^{\mathrm{a}}$ Averages across 30 provinces.

${ }^{\mathrm{b}}$ Measured in 10,000 yuan per worker.

${ }^{\mathrm{c}}$ Measured in $100 \mathrm{M}$ yuan.

${ }^{\mathrm{d}}$ Measured in 10,000s of workers.

Table 2: Explaining Labor Productivity: A Random Effects Model ${ }^{\mathrm{a}}$

\begin{tabular}{lrr} 
Parameter & Estimate & $\mathrm{t}$-stat \\
\hline Intercept & 0.554 & 2.38 \\
Capital/Labor & 0.282 & 12.7 \\
Labor (/1000) & -0.370 & 0.49 \\
Public Capital (/1000) & 2.995 & 9.23 \\
Year 1995 & -0.244 & 2.22 \\
Year 1996 & -0.295 & 2.61 \\
Year 1997 & -0.368 & 3.03 \\
Year 1998 & -0.235 & 1.50 \\
Year 1999 & -0.848 & 4.58 \\
Year 2000 & -0.349 & 1.59 \\
\hline Var(random effect) & 0.676 & \\
Var(disturbance) & 0.424 & \\
$\mathrm{R}^{2}$ & 0.756 & \\
\hline Hausman test value of $\chi^{2}(9)=2.22$ has a $p$-value of 0.988
\end{tabular}


Table 3: Choosing from Alternative Correlation Structures

\begin{tabular}{|c|c|c|c|c|c|c|}
\hline $\begin{array}{l}\text { Correlation } \\
\text { structure }\end{array}$ & $\begin{array}{l}\text { Log-likelihood } \\
\text { value }\end{array}$ & $D_{1}$ & $\mathrm{D}_{2}$ & $2{ }_{1}$ & $2_{2}$ & $2_{3}$ \\
\hline \multicolumn{7}{|c|}{ A: Cost function model } \\
\hline Uncorrelated & -36.353 & & & & & \\
\hline $\mathrm{C}_{1}$ & 302.249 & 0.937 & & & & \\
\hline $\mathrm{C}_{1}, 1_{1}$ & 336.746 & 0.939 & & 0.463 & & \\
\hline$C_{1}, 1_{2}$ & 349.373 & 0.940 & & & 0.516 & \\
\hline $\mathrm{C}_{1}, 1_{3}$ & 437.568 & 0.932 & & & & 0.502 \\
\hline $\mathrm{C}_{2}$ & 275.892 & & 0.864 & & & \\
\hline $\mathrm{C}_{2}, 1_{1}$ & 304.408 & & 0.857 & 0.429 & & \\
\hline $\mathrm{C}_{2}, \mathrm{I}_{2}$ & 312.207 & & 0.856 & & 0.470 & \\
\hline $\mathrm{C}_{2}, \mathrm{1}_{3}$ & 392.184 & & 0.851 & & & 0.495 \\
\hline lowest $t$-stat & & 70.99 & 31.53 & 10.69 & 12.87 & 5.64 \\
\hline \multicolumn{7}{|c|}{ B: Profit function model } \\
\hline Uncorrelated & -607.395 & & & & & \\
\hline $\mathrm{C}_{1}$ & -456.184 & 0.767 & & & & \\
\hline $\mathrm{C}_{1}, \mathrm{1}_{1}$ & -451.550 & 0.774 & & 0.314 & & \\
\hline $\mathrm{C}_{1}, \mathrm{1}_{2}$ & -450.118 & 0.777 & & & 0.367 & \\
\hline $\mathrm{C}_{1}, 1_{3}$ & -447.217 & 0.816 & & & & 0.083 \\
\hline $\mathrm{C}_{2}$ & -449.670 & & 0.762 & & & \\
\hline $\mathrm{C}_{2}, 1_{1}$ & -446.143 & & 0.770 & 0.280 & & \\
\hline $\mathrm{C}_{2}, \mathrm{1}_{2}$ & -444.939 & & 0.774 & & 0.342 & \\
\hline $\mathrm{C}_{2}, 1_{3}$ & -443.367 & & 0.805 & & & 0.062 \\
\hline lowest $t$-stat & & 25.55 & 17.43 & 3.65 & 3.78 & 2.04 \\
\hline
\end{tabular}


Table 4: Cost and Profit Function Estimates

A: Cost Function Model

\begin{tabular}{|c|c|c|c|c|c|c|c|c|c|}
\hline \multirow{3}{*}{ Using: } & & & \\
\hline & \multicolumn{2}{|c|}{$\mathrm{C}_{1}, 1_{3}$} & \multicolumn{2}{|c|}{$\mathrm{C}_{2}, \mathrm{I}_{3}$} & & \multicolumn{2}{|c|}{$\mathrm{C}_{1}, \mathrm{I}_{3}$} & \multicolumn{2}{|c|}{$\mathrm{C}_{2}, \mathrm{I}_{3}$} \\
\hline & Estimate & $t$-stat & Estimate & $t$-stat & & Estimate & $t$-stat & Estimate & $t$-stat \\
\hline$"{ }_{0}$ & -0.004 & 0.01 & 0.915 & 1.65 & 10 & -5.144 & 3.15 & -3.573 & 2.24 \\
\hline$"{ }_{L}$ & 0.520 & 6.92 & 0.509 & 7.93 & $l_{Y}$ & 3.689 & 3.85 & 3.955 & 4.50 \\
\hline$"{ }_{Y}$ & 0.897 & 8.17 & 0.865 & 7.95 & $i_{L}$ & -1.917 & 4.54 & -1.841 & 4.62 \\
\hline$"{ }_{G}$ & 0.620 & 3.14 & 0.317 & 2.25 & $\left(_{G}\right.$ & 1.711 & 7.17 & 1.304 & 5.52 \\
\hline$"{ }_{t}$ & 0.038 & 0.54 & 0.071 & 1.31 & $l_{t}$ & -0.128 & 0.68 & 0.083 & 0.52 \\
\hline$\$_{L L}$ & 0.157 & 15.57 & 0.147 & 15.17 & $*_{Y Y}$ & -0.913 & 2.86 & -1.043 & 3.49 \\
\hline$\$_{L Y}$ & 0.027 & 1.93 & 0.019 & 1.77 & $*_{Y L}$ & 0.812 & 4.96 & 0.904 & 6.22 \\
\hline$\$_{L G}$ & -0.032 & 1.63 & -0.018 & 1.26 & $*_{Y G}$ & -0.177 & 1.64 & -0.172 & 1.88 \\
\hline$\$_{L t}$ & -0.047 & 5.43 & -0.049 & 9.18 & $*_{Y T}$ & -0.100 & 1.41 & -0.142 & 2.34 \\
\hline$\$_{Y Y}$ & 0.025 & 0.81 & 0.032 & 1.21 & $*_{L L}$ & -0.776 & 5.65 & -0.847 & 7.23 \\
\hline$\$_{Y G}$ & -0.070 & 2.08 & -0.047 & 1.91 & $*_{L G}$ & 0.119 & 2.12 & 0.065 & 1.18 \\
\hline$\$_{Y t}$ & -0.003 & 0.47 & -0.007 & 1.80 & $*_{L T}$ & 0.094 & 3.07 & 0.124 & 5.01 \\
\hline$\$_{t t}$ & 0.000 & 0.01 & 0.002 & 0.11 & $*_{t t}$ & 0.020 & 0.71 & -0.003 & 0.14 \\
\hline $\mathrm{F}_{C C}$ & 0.167 & 4.18 & 0.142 & 4.06 & $\mathrm{~F}_{\mathrm{AA}}$ & 0.463 & 6.79 & 0.637 & 5.27 \\
\hline $\mathrm{D}_{C L}$ & -0.198 & 2.10 & -0.172 & 1.94 & $\mathrm{D}_{\mathrm{AY}}$ & -0.653 & 15.24 & -0.628 & 14.26 \\
\hline $\mathrm{D}_{C Y}$ & -0.719 & 15.41 & -0.724 & 16.71 & $\mathrm{D}_{\mathrm{AL}}$ & 0.668 & 16.02 & 0.650 & 15.53 \\
\hline $\mathrm{F}_{L L}$ & 0.016 & 4.02 & 0.012 & 4.24 & $\mathrm{~F}_{Y Y}$ & 24.804 & 5.00 & 22.059 & 4.27 \\
\hline $\mathrm{D}_{L Y}$ & 0.092 & 0.96 & 0.166 & 1.76 & $\mathrm{D}_{Y L}$ & -0.991 & 784.26 & -0.987 & 530.22 \\
\hline $\mathrm{F}_{Y Y}$ & 2.733 & 4.21 & 2.143 & 4.29 & $\mathrm{~F}_{L L}$ & 2.417 & 5.03 & 2.188 & 4.28 \\
\hline$D_{1}$ & 0.932 & 70.99 & & & $D_{1}$ & 0.816 & 29.12 & & \\
\hline$D_{2}$ & & & 0.851 & 32.05 & $D_{2}$ & & & 0.805 & 19.51 \\
\hline $2_{3}$ & 0.502 & 5.98 & 0.495 & 5.64 & $\underline{2_{3}}$ & 0.083 & 2.26 & 0.062 & 2.04 \\
\hline $\log$ lik. & 437.57 & & 392.18 & & & -447.22 & & -443.37 & \\
\hline
\end{tabular}

B: Profit Function Model $\mathrm{C}_{1}, \mathrm{1}_{3} \quad \mathrm{C}_{2}, \mathrm{1}_{3}$ 
Table 5: Decomposition of Labor Productivity Growth ${ }^{\text {a }}$

\begin{tabular}{|c|c|c|c|c|c|c|c|c|c|c|c|}
\hline \multirow[b]{2}{*}{ period } & observe & \multicolumn{5}{|c|}{ Using $C_{1}, 1_{3}$} & \multicolumn{5}{|c|}{ Using $C_{2}, 1_{3}$} \\
\hline & $\mathrm{d}$ & $?_{K / L}$ & $?_{L}$ & $?_{G}$ & $?_{t}$ & total & $?_{K / L}$ & $?_{L}$ & $?_{G}$ & $?_{t}$ & total \\
\hline \multicolumn{12}{|c|}{ A: Cost Function Model } \\
\hline \multirow[t]{2}{*}{ 1994-95 } & -0.078 & 0.036 & 0.000 & -0.032 & 0.103 & 0.107 & 0.033 & 0.000 & -0.003 & 0.086 & 0.116 \\
\hline & & 0.007 & 0.001 & 0.013 & 0.083 & 0.082 & 0.006 & 0.000 & 0.007 & 0.059 & 0.059 \\
\hline \multirow[t]{2}{*}{$1995-96$} & 0.142 & 0.088 & -0.008 & -0.038 & 0.071 & 0.113 & 0.077 & -0.004 & -0.005 & 0.054 & 0.122 \\
\hline & & 0.012 & 0.002 & 0.015 & 0.065 & 0.065 & 0.009 & 0.001 & 0.008 & 0.043 & 0.043 \\
\hline \multirow[t]{2}{*}{$1996-97$} & 0.133 & 0.098 & -0.013 & -0.042 & 0.064 & 0.108 & 0.085 & -0.007 & -0.005 & 0.046 & 0.120 \\
\hline & & 0.011 & 0.004 & 0.017 & 0.050 & 0.048 & 0.008 & 0.002 & 0.009 & 0.027 & 0.027 \\
\hline \multirow[t]{2}{*}{$1997-98$} & 0.331 & 0.219 & -0.111 & -0.044 & 0.061 & 0.124 & 0.189 & -0.059 & -0.005 & 0.041 & 0.166 \\
\hline & & 0.024 & 0.028 & 0.019 & 0.045 & 0.044 & 0.016 & 0.015 & 0.009 & 0.019 & 0.021 \\
\hline \multirow[t]{2}{*}{ 1998-99 } & -0.001 & 0.099 & -0.033 & -0.040 & 0.075 & 0.102 & 0.087 & -0.018 & -0.003 & 0.052 & 0.117 \\
\hline & & 0.011 & 0.008 & 0.017 & 0.053 & 0.049 & 0.007 & 0.004 & 0.009 & 0.028 & 0.026 \\
\hline \multirow[t]{2}{*}{$1999-00$} & 0.278 & 0.111 & -0.040 & -0.046 & 0.089 & 0.114 & 0.098 & -0.023 & -0.005 & 0.062 & 0.131 \\
\hline & & 0.012 & 0.009 & 0.018 & 0.072 & 0.068 & 0.008 & _. & _. 0.009 & - 0.046 & 0.044 \\
\hline \multicolumn{12}{|c|}{ B: Profit Function Model } \\
\hline \multirow[t]{2}{*}{$1994-95$} & -0.078 & 0.025 & 0.000 & 0.129 & -0.142 & 0.013 & 0.027 & 0.000 & 0.079 & -0.056 & 0.050 \\
\hline & & 0.008 & 0.001 & 0.016 & 0.064 & 0.061 & 0.007 & 0.001 & 0.014 & 0.045 & 0.044 \\
\hline \multirow[t]{2}{*}{$1995-96$} & 0.142 & 0.037 & 0.012 & 0.140 & -0.125 & 0.064 & 0.039 & 0.012 & 0.090 & -0.048 & 0.092 \\
\hline & & 0.014 & 0.002 & 0.019 & 0.054 & 0.050 & 0.013 & 0.001 & 0.016 & 0.037 & 0.037 \\
\hline \multirow[t]{2}{*}{$1996-97$} & 0.133 & 0.034 & 0.020 & 0.158 & -0.113 & 0.100 & 0.035 & 0.020 & 0.108 & -0.045 & 0.114 \\
\hline & & 0.013 & 0.003 & 0.022 & 0.043 & 0.035 & 0.013 & 0.003 & 0.019 & 0.030 & 0.025 \\
\hline \multirow[t]{2}{*}{$1997-98$} & 0.331 & 0.066 & 0.166 & 0.179 & -0.102 & 0.309 & 0.063 & 0.166 & 0.122 & -0.045 & 0.306 \\
\hline & & 0.026 & 0.023 & 0.026 & 0.036 & 0.028 & 0.026 & 0.024 & 0.022 & 0.026 & 0.018 \\
\hline \multirow[t]{2}{*}{ 1998-99 } & -0.001 & 0.027 & 0.046 & 0.167 & -0.075 & 0.165 & 0.025 & 0.047 & 0.115 & -0.032 & 0.155 \\
\hline & & 0.012 & 0.006 & 0.025 & 0.033 & 0.032 & 0.012 & 0.007 & 0.021 & 0.026 & 0.019 \\
\hline \multirow[t]{2}{*}{ 1999-00 } & 0.278 & 0.028 & 0.055 & 0.184 & -0.058 & 0.208 & 0.024 & 0.058 & 0.129 & -0.029 & 0.182 \\
\hline & & 0.014 & 0.009 & 0.029 & 0.043 & 0.048 & 0.014 & 0.009 & 0.024 & 0.035 & 0.033 \\
\hline
\end{tabular}

a For each annual period, the first line reports the estimated contribution to labor productivity growth and the second line gives the standard error of the estimate. 
Table 6: Productivity Growth Among Provinces in China

\begin{tabular}{|c|c|c|c|c|c|c|}
\hline & \multirow[b]{2}{*}{$\begin{array}{l}\text { initial labor } \\
\text { productivity }\end{array}$} & \multirow[b]{2}{*}{$\begin{array}{l}\text { growth in labor } \\
\text { productivity, } \\
\text { 1993/4-2000 } \\
\text { (percent) }\end{array}$} & \multicolumn{4}{|c|}{ Predicted growth in labor productivity } \\
\hline & & & $\begin{array}{c}\text { Cost } \\
\text { model, } \\
\text { using } \\
1_{1}, C_{3} \\
\end{array}$ & $\begin{array}{c}\text { Cost } \\
\text { model, } \\
\text { using } \\
1_{2}, \mathrm{C}_{3}\end{array}$ & $\begin{array}{l}\text { Profit } \\
\text { model, } \\
\text { using } \\
1_{1}, \mathrm{C}_{3} \\
\end{array}$ & $\begin{array}{c}\text { Profit } \\
\text { model, } \\
\text { using } \\
1_{2}, \mathrm{C}_{3}\end{array}$ \\
\hline $\begin{array}{l}10 \text { provinces with highest initial } \\
\text { labor productivity }\end{array}$ & 2.58 & 159.2 & 117.3 & 131.7 & 126.9 & 131.0 \\
\hline $\begin{array}{l}10 \text { provinces with medium initial } \\
\text { labor productivity }\end{array}$ & 1.46 & 132.9 & 83.6 & 101.9 & 125.3 & 130.3 \\
\hline $\begin{array}{l}10 \text { provinces with lowest initial } \\
\text { labor productivity }\end{array}$ & 1.14 & 118.5 & 67.9 & 88.1 & 115.5 & 128.4 \\
\hline $\begin{array}{l}\text { correlation between observed } \\
\text { and predicted labor productivity } \\
\text { growth }\end{array}$ & & & 0.55 & 0.62 & 0.25 & 0.31 \\
\hline $\begin{array}{l}\text { correlation between initial labor } \\
\text { productivity and predicted labor } \\
\text { productivity growth }\end{array}$ & & & 0.69 & 0.68 & -0.01 & -0.03 \\
\hline
\end{tabular}

